Andrés Jesús Villalba ${ }^{1}$ María Eugenia Marichal ${ }^{2}$

\title{
EVOLUCIÓN DE LA REGULACIÓN JURÍDICA SOBRE SEGURIDAD ALIMENTARIA DE LAS PERSONAS CELÍACAS EN ARGENTINA
}

Evolution of Food Safety regulation for celiac people in Argentina

${ }^{1}$ Universidad Nacional del Litoral. Facultad de Ciencias Jurídicas y Sociales. Santa Fe, Argentina.

${ }^{2}$ Universidad Nacional del Litoral. Facultad de Ciencias Jurídicas y Sociales. Centro de investigaciones en Derecho. Santa Fe, Argentina.

Correspondência: Andrés Jesús Villalba. E-mail: andresjesusvillalba@hotmail.com.

Recebido em: 25/04/2019. Revisado em: 03/11/2019. Aprovado em: 28/02/2020. 


\section{RESUMO}

El presente trabajo explora el ordenamiento jurídico argentino para reconstruir sistemáticamente el marco protectorio de la seguridad alimentaria de las personas celíacas. Se trata centralmente de analizar la Ley Nacional de Celiaquía No26.588 que constituye la base normativa para su protección. Se relevan también otras normas importantes del marco protectorio de la salud en términos amplios, como son las normas de derecho del consumidor. El objetivo es determinar cuáles son los elementos normativos que efectivamente inciden sobre la seguridad alimentaria de la población celíaca. Así también, se trata de establecer cuál es el nivel de protección de su derecho, constitucionalmente reconocido, a una alimentación adecuada. En términos metodológicos, el trabajo se basa centralmente en un análisis documental clásico del conjunto de normas jurídicas indicado. Las claves de análisis normativo se construyeron a partir de otras fuentes documentales complementarias como manuales de buenas prácticas o publicaciones de acceso abierto editadas por asociaciones de las personas celíacas. En primer lugar, se realiza una breve descripción de la enfermedad celíaca y de las principales problemáticas que afectan a la población celíaca en relación al concepto de seguridad alimentaria. Luego, se ordena cronológicamente la construcción del reciente marco normativo nacional que tutela a la población celíaca. En tercer lugar, se analiza la legislación vigente a fin de identificar tanto los derechos que reconoce el Estado nacional como los instrumentos que diseña para hacerlos efectivos. Por último, se esbozan algunas líneas a modo de conclusión.

\section{Palabras clave}

Derecho a una Alimentación Adecuada; Legislación nacional de Celiaquía; Personas Celíacas; Seguridad Alimentaria

\section{ABSTRACT}

This paper explores the Argentine legal system to systematically reconstruct the protective framework of food safety for people with celiac disease. The main focus is to analyze the National Law for Celiac Disease no. 26588, which constitutes the normative basis for its protection. Other important norms of protective framework of health are also revealed in broad terms, such as consumer law norms. The objective is to identify the normative elements that effectively affect the food safety of the celiac population. Likewise, is it a matter of establishing the level of protection of their constitutionally recognized right to adequate food. In methodological terms, the work is based on a classic documentary analysis of the set of legal norms indicated. The normative analysis keys were constructed from other complementary documentary sources such as manuals of good practice or open access publications edited by associations of people with celiac disease. First, a brief description of celiac disease and the main problems affecting the celiac population in relation to the concept of food safety is described. Then, the construction of the recent national regulatory framework that protects the celiac population is chronologically ordered. Third, current legislation is analyzed in order to identify both the rights recognized by the national State and the instruments designed to make them effective. Finally, some concluding remarks are outlined.

\section{Keywords}

Right to Adequate Food; National Celiac Disease Legislation; Celiac Disease; People with Celiac Disease; Food Safety. 


\section{Introducción}

En la última década, el Estado argentino ha propiciado un desarrollo legislativo tendiente a garantizar la seguridad alimentaria de las personas que padecen la enfermedad de celiaquía. Esta progresiva regulación jurídica representa un importante paso hacia la internalización de los estándares establecidos por Tratados Internacionales que consagran los derechos a la salud y a una alimentación adecuada considerados como derechos humanos. Estos derechos humanos conforman el denominado Bloque de Constitucionalidad argentino.

Tanto el derecho a la salud como el derecho a la alimentación adecuada pertenecen a la difundida clasificación de "derechos económicos, sociales y culturales". El Estado argentino ha otorgado jerarquía constitucional a varios tratados internacionales de derechos humanos, que consagran estos derechos: Convención sobre los Derechos de las Personas con Discapacidad ${ }^{1}$ (art. 25 y 28); Convención sobre los Derechos del Niño (art. 24); Convención sobre Eliminación de todas las formas de Discriminación contra la Mujer $^{3}$ (art. 11); Pacto Internacional de Derechos Económicos, Sociales y Culturales ${ }^{4}$ (art. 11 y 12); Convención Americana sobre Derechos Humanos ${ }^{5}$ (art. 26); Declaración Universal de Derechos Humanos ${ }^{6}$ (art. 25); Declaración Americana de los Derechos y Deberes del Hombre (art. XI); Protocolo Facultativo de San Salvador ${ }^{8}$ (art. 10 y 12).

El presente trabajo pretende relevar el ordenamiento jurídico argentino para reconstruir sistemáticamente el marco protectorio de la seguridad alimentaria de las personas celíacas. Centralmente, se trata de analizar la Ley $\mathrm{N}^{\circ} 26.588^{9}$, conocida como Ley Nacional de Celiaquía (LNC), la cual brinda la base normativa

\footnotetext{
${ }^{1}$ NACIONES UNIDAS. Convención sobre los Derechos de las Personas con Discapacidad. Disponible en: https://www.un.org/esa/socdev/enable/documents/tccconvs.pdf. Acceso en: 13 ago. 2021.

${ }^{2}$ UNICEF. Convención sobre los Derechos del Niño. Disponible en: https://www.unicef.es/sites/unicef.es/ files/comunicacion/ConvencionsobrelosDerechosdelNino_0.pdf. Acceso en: 13 ago. 2021.

${ }^{3} \mathrm{NACIONES}$ UNIDAS. Convención sobre Eliminación de todas las formas de Discriminación contra la Mujer. Disponible en: ohchr.org/sp/professionalinterest/pages/cedaw.aspx. Acceso en: 13 ago. 2021.

${ }^{4}$ NACIONES UNIDAS. Pacto Internacional de Derechos Económicos, Sociales y Culturales. Disponible en: https://www.ohchr.org/sp/professionalinterest/pages/cescr.aspx. Acceso en: 13 ago. 2021.

${ }^{5}$ ORGANIZACIÓN DE LOS ESTADOS AMERICANOS - OEA. Convención Americana sobre Derechos Humanos. Disponible en: https://www.oas.org/dil/esp/tratados_b-32_convencion_americana_sobre_derechos_humanos. htm. Acceso en: 13 ago. 2021.

${ }^{6}$ NACIONES UNIDAS. Declaración Universal de Derechos Humanos. Disponible en: https://www.un.org/es/ about-us/universal-declaration-of-human-rights. Acceso en: 13 ago. 2021.

7ORGANIZACIÓN DE LOS ESTADOS AMERICANOS - OEA. Declaración Americana de los Derechos y Deberes del Hombre. Disponible en: http://www.oas.org/es/cidh/mandato/Basicos/declaracion.asp. Acceso en: 13 ago. 2021.

${ }^{8}$ ORGANIZACIÓN DE LOS ESTADOS AMERICANOS - OEA. Protocolo Adicional a la Convención Americana sobre Derechos Humanos en Materia de Derechos Económicos, Sociales y Culturales - Protocolo de San Salvador. Disponible en: http://www.oas.org/es/sadye/inclusion-social/protocolo-ssv/docs/protocolo-sansalvador-es.pdf. Acceso en: 13 ago. 2021.

${ }^{9}$ CONGRESO DE LA NACIÓN ARGENTINA. Ley 26.588, de 02 de diciembre de 2009. Congreso de la Nación Argentina. 02-dic-2009. Declara de interés nacional la atención médica, la investigación clínica y epidemiológica, la capacitación profesional en la detección temprana, diagnóstico y tratamiento de la enfermedad celíaca. Disponible en: http://servicios.infoleg.gob.ar/infoleglnternet/verNorma. do;jsessionid=5EEE9F15ADDE5B03A856B2B2542EC1D7?id=162428. Acceso en: 01 abr. 2019.
} 
para la protección de las personas con celiaquía. Se relevan también otras normas que componen el marco protectorio de la salud de las personas celíacas en términos amplios, como son las normas de derecho del consumidor (dada la particularidad de esta afección, íntimamente vinculada a los alimentos que se consumen).

No se trata de realizar un digesto normativo de una problemática específica, sino de relevar el ordenamiento jurídico con el objetivo de indagar cuáles son los elementos normativos que efectivamente inciden sobre la seguridad alimentaria de la población celíaca. Asimismo, se intenta diagnosticar el grado de protección de sus derechos constitucionalmente reconocidos a la salud y a una alimentación adecuada.

En términos metodológicos, el trabajo se basa en un análisis documental clásico del conjunto de normas jurídicas indicado. Las claves de relevamiento y análisis del mapeo normativo se construyeron a partir del estudio de otras fuentes documentales complementarias: normativa no vinculante emanada de organismos públicos nacionales de control en la materia (guías de manipulación de alimentos, manuales de buenas prácticas, etc.) y publicaciones de acceso abierto editadas por asociaciones de las personas celíacas. Estas últimas cuentan con notas de divulgación de profesionales de la salud (centralmente médicos y nutricionistas) y notas elaboradas por la propia comunidad de personas celíacas. Si bien está más allá de lo estrictamente jurídico, consideramos que esta fuente documental es de particular interés para la comprensión de la construcción, interpretación y aplicación de la normativa analizada y la determinación de su grado de efectividad.

En primer lugar, se realiza una breve descripción de la enfermedad celíaca y de las principales problemáticas que afectan a la población celíaca en relación al concepto de seguridad alimentaria acuñado en el derecho internacional. Luego, se releva cronológicamente la construcción del reciente marco normativo nacional que tutela a la población celíaca. En tercer lugar, se analiza la legislación vigente a fin de identificar tanto los derechos que reconoce el Estado nacional como los instrumentos que diseña para hacerlos efectivos.

Luego, a los fines de diagnosticar la efectividad del marco normativo reconstruido se analizan antecedentes jurisprudenciales e informes producidos sobre los precios de los alimentos sin trigo, avena, cebada y centeno (sin T.A.C.C.)

Por último, se esbozan algunas líneas a modo de conclusión.

\section{Celiaquía y derecho a la alimentación}

\section{Celiaquía y seguridad alimentaria}

Podemos definir a la celiaquía como

una intolerancia a las proteínas del gluten (gliadinas, secalinas, hordeínas y, posiblemente, aveninas) que cursa con una 
atrofia severa de la mucosa del intestino delgado superior. Como consecuencia, se establece un defecto de utilización de nutrientes (principios inmediatos, sales y vitaminas) a nivel del tracto digestivo, cuya repercusión clínica y funcional va a estar en dependencia de la edad y la situación fisiopatológica del paciente. Esta intolerancia es de carácter permanente, se mantiene a lo largo de toda la vida y se presenta en sujetos genéticamente predispuestos a padecerla ${ }^{10}$.

Esta intolerancia trae aparejadas diversas complicaciones en la salud de las personas, tales como "osteoporosis, anemia crónica, abortos espontáneos, infertilidad, colon irritable, dolor abdominal, convulsiones, depresión, cansancio crónico, entre otras"11.

Al presente, la celiaquía es una de las enfermedades con mayor grado de prevalencia en el mundo. Se estima que cerca del 1\% de la población mundial padece celiaquía, lo que significa que alrededor de 700 millones de personas son celíacas ${ }^{12}$. En Argentina, esta cifra ascendería a aproximadamente $400 \mathrm{mil}$ individuos. En el marco del Programa Nacional de Detección y Control de la Enfermedad Celíaca se explica que aunque no exista un registro de casos, ciertos estudios preliminares en Argentina señalan una prevalencia de aproximadamente 1: 200. En ese informe se calculaba, para el año 2007, que 1 de cada 100 personas era celíaca (habría aproximadamente 400 mil celíacos en Argentina). Por lo tanto 400 mil familias deben adaptarse al estilo de vida del integrante celíaco ${ }^{13}$. Más allá de estos datos, se considera que la epidemiología de la celiaquía tiene las características de un iceberg, puesto que un porcentaje importante de casos permanece sin diagnosticar ${ }^{14}$.

La persona celíaca es un desnutrido "invisible" u "oculto" ya que si bien se alimenta diariamente, su condición le impide asimilar macro y micronutrientes. El único tratamiento eficaz y disponible para la enfermedad celíaca es "llevar una dieta estricta y permanente libre de gluten (sin T.A.C.C.) que permita la regeneración

\footnotetext{
${ }^{10}$ POLANCO ALLUÉ, Isabel; RIBES KONINCKX, Carmen. Enfermedad celíaca. Pediatría Integral, v. 1, n. 2, p. 47, 1995.Disponible en: https://docplayer.es/6774608-Enfermedad-celiaca-isabel-polanco-allue-1-carmenribes-koninckx-2.html.

${ }^{11}$ PELLICER, K. et al. Actualización en legislación de alimentos para celíacos. Analecta Veterinaria, v. 34, n. 1-2, p. 27, 2014. Disponible en: http://sedici.unlp.edu.ar/bitstream/handle/10915/45518/ Documento_completo.pdf?sequence=1\&isAllowed=y.

${ }^{12}$ ld. Ibid.

${ }^{13}$ La fundamentación completa de la creación del mencionado Programa se encuentra en ARGENTINA. Ministerio de Salud. Resolución 1560/2007, de 27 noviembre 2007. Créase el Programa Nacional de Detección y Control de la Enfermedad Celiaca, a fin de contribuir a la detección temprana de la enfermedad y al fortalecimiento del sistema nacional de control de alimentos. Disponible en: http://servicios.infoleg. gob.ar/infolegInternet/verNorma.do?id=135022. Acceso en: 01 abr. 2019.

${ }^{14} \mathrm{JACOBI}, \mathrm{M}$. F. et al. Menúes aptos para celíacos y conocimiento de los manipuladores de alimentos en los servicios gastronómicos comerciales de la ciudad de Santa Fe. Actualización en Nutrición, v. 18, n. 4, p. 108-114, 2017.
} 
de las vellosidades intestinales"15. Lo que preliminarmente representa un tratamiento relativamente sencillo de ejecutar, en la práctica se torna dificultoso.

Antes de analizar las problemáticas cotidianas que enfrentan las personas celíacas, es menester revisar los elementos del concepto de seguridad alimentaria y del derecho a una alimentación adecuada. La Organización de las Naciones Unidas para la Alimentación y Agricultura (FAO) establece que

existe seguridad alimentaria cuando todas las personas tienen en todo momento acceso físico y económico a suficientes alimentos inocuos y nutritivos para satisfacer sus necesidades alimenticias y sus preferencias en cuanto a los alimentos a fin de llevar una vida activa y sana ${ }^{16}$.

En 1996, durante la primera Cumbre sobre alimentación que tuvo lugar en Roma, se advirtió a nivel internacional la preocupación sobre el problema del hambre como una responsabilidad global, y se definió a la alimentación como un derecho humano. El derecho a la alimentación ya había sido reconocido como tal en 1966 en el Pacto Internacional de Derechos Económicos, Sociales y Culturales (PIDESC) (art. 11) y antes en la Declaración de Derechos Humanos de 1948. Pero es recién con la Cumbre Mundial que se comienza a organizar una agenda mundial en estos temas ${ }^{17}$.

El concepto de alimentación adecuada se define en términos amplios para comprender la disponibilidad de alimentos en cantidad y calidad suficiente, la seguridad de los alimentos tanto en términos de inocuidad como en relación a su aceptabilidad cultural. Su estatus legal de derecho humano social y económico ha sido cuestionado, en el sentido de discutir su consideración como un derecho subjetivo exigible, indicando que debería ser comprendido como un simple objetivo político ${ }^{18}$. En este trabajo sostenemos, como lo hace la mayoría de la literatura del campo de derecho alimentario, que existen desarrollos

\footnotetext{
${ }^{15}$ PELLICER, K. et al. op. cit., p. 27.

${ }^{16}$ ORGANIZAÇÃO das Nações Unidas para a Alimentação e a Agricultura - FAO. La Utilización de los principios del análisis de riesgos y de los puntos críticos de control en el control de alimentos. Vancouver: Food\&AgricultureOrg., 1996.

${ }^{17}$ Una completa cronología del reconocimiento del derecho humano a la alimentación puede consultarse en: ORGANIZAÇÃO das Nações Unidas para a Alimentação e a Agricultura - FAO. Cronología del Derecho a la Alimentación. Disponible en: http://www.fao.org/right-to-food-timeline/es. Acceso en: 25 sept. 2018. Para un análisis más detallado acerca del derecho humano a la alimentación adecuada consagrado en el PIDESC (art. 11) véase BONET DE VIOLA, Ana María. Entre seguridad, soberanía y democracia alimentaria: consecuencias políticas de una disgregación terminológica. Derecho y Justicia, v. 4, p. 7-23, 2014. Disponible en: https://www.researchgate.net/publication/303786105_ Entre_seguridad_soberania_y_democracia_alimentaria_Consecuencias_politicas_de_una_ disgregacion_terminologica.

${ }^{18}$ MEULEN, B. M. J. van der; RĂTESCU, loana. Food prints on human rights law paradigms. Wageningen: European Institute for Food Law, 2017. Disponible en: https://ssrn.com/abstract=3056750.
} 
legislativos suficientes ${ }^{19}$ como para considerar que el derecho a la alimentación es un derecho humano ${ }^{20}$.

La FAO reconoce que la seguridad alimentaria tiene cuatro componentes básicos: disponibilidad, estabilidad, accesibilidad -física y económica- y adecuabilidad. En los siguientes apartados, analizaremos la "accesibilidad" (tanto en su ámbitofísico como económico) y la vital importancia que adquiere el derecho a la información en esta afectación particular de la celiaquía.

\section{El acceso físico a los alimentos}

El mayor problema en relación a la seguridad alimentaria mundial no radica en la disponibilidad de alimentos sino en la cuestión de su acceso y distribución, lo cual ha sido suficientemente estudiado y documentado ${ }^{21}$. En relación al requisito del acceso como componente de la seguridad alimentaria, se ha señalado que la falta de acceso físico "se produce cuando existe una cantidad insuficiente de alimentos para satisfacer las necesidades nutricionales de la población”22.

En materia de celiaquía y, específicamente, analizando el caso argentino, esta falta de acceso físico a alimentos libres de gluten está dada por varias circunstancias. El gluten es una prolamina que se encuentra presente en la mayor parte de los alimentos industrializados disponibles en el mercado ya sea por contenerlo de manera directa (v. gr. productos elaborados a base de trigo, avena, cebada o centeno) o de manera indirecta ${ }^{23}$ (v. gr. a través de emulsionantes, aglutinantes, conservantes u otros aditivos que contienen gluten). Sucede frecuentemente que las personas celíacas no encuentran en el mercado nacional productos sustitutivos de los alimentos de consumo básico, que sean libres de gluten y le permitan sobrellevar adecuadamente su enfermedad, en cantidad, variedad suficiente y precio razonable para mantener una dieta balanceada. Esta afirmación se limita a los alcances territoriales del análisis de este trabajo, es decir, la Argentina y se basa en las numerosas

\footnotetext{
${ }^{19} \mathrm{KNUTH}$, Lidija; VIDAR, Margret. Constitutional and legal protection of the right to food around the world. Roma: FAO, 2011. (RighttoFoodStudies). Disponible en: http://www.fao.org/docrep/016/ap554e/ ap554e.pdf.

${ }^{20}$ MEULEN, B. M. J. van der. The functional field of food law. The emergence of a functional discipline in the legal sciences. Wageningen: European Institute for Food Law, 2018. (Working Paper). Disponible en: https://ssrn.com/abstract=3128103; NACIONES UNIDAS. Consejo Económico y Social. El derecho a una alimentación adecuada (art. 11). E/C.12/1999/5, CESCR Observación General 12 (General Comments). Ginebra: ONU, 1999. Disponible en: https://www.acnur.org/fileadmin/Documentos/BDL/2001/1450.pdf.

${ }^{21}$ En este sentido, una referencia ineludible son las investigaciones de SEN, Amartya. Poverty and famines. Oxford: Oxford University Press, 2005.

${ }^{22}$ ORGANIZAÇÃO das Nações Unidas para a Alimentação e a Agricultura - FAO. La Seguridad Alimentaria: una información importante para la toma de decisiones. Guía Práctica 2011. Disponible en: http://www.fao. org/3/al936s/al936s00.pdf. Acceso en: 04 abr. 2019.

${ }^{23}$ MEDINA, G.; LUFT, E. Los celíacos y las obligaciones de las obras sociales y empresas de medicina prepaga. La Ley, Buenos Aires, p. 1-12, 2010.
} 
denuncias, reclamos y opiniones vertidas en la publicación periódica denominada Revista Mundo Celíaco ${ }^{24}$.

En este sentido, el director del Centro de Oleaginosas y Cereales del Instituto Nacional de Tecnología Industrial (INTI) advierte que el mercado de productos derivados de granos, destinados a personas celíacas, tiene una oferta reducida e inadecuada, debido a que el sector industrial ligado a la fabricación de alimentos sin T.A.C.C. se enfrenta a situaciones adversas ${ }^{25}$. Señala por tales a la escasez de materias primas adecuadas para su elaboración, como así también, la utilización de productos (goma guar o xántica) que, en pos de mejorar la textura y características funcionales y sensoriales del alimento, encarecen decididamente su valor.

Por todo ello, en Argentina, los productos sin T.A.C.C se encuentran destinados a un número reducido de consumidores, lo que se traduce en una demanda ínfima -en comparación con la demanda de alimentos con T.A.C.C-. Se trata además, de una producción de alimentos con costos diametralmente superiores a sus similares con gluten. Esto se debe a la necesidad de una logística especial para el transporte y la distribución, la incorporación de tecnología específica que evite la contaminación cruzada, la necesidad de capacitar todos los empleados de la planta, y el cumplimiento de requisitos adicionales para su registro y autorización ${ }^{26}$. Todo ello torna al producto sin T.A.C.C. en un activo poco atractivo para el mercado de los productores de alimentos y las cadenas de comercialización. En los relatos de productores, distribuidores y comerciantes de productos aptos para celíacos que recoge la mencionada publicación Mundo Celíaco, se observa que la motivación central para llevar adelante estos emprendimientos era sufrir en primera persona o por algún miembro de la familia, las limitaciones en la disponibilidad de alimentos ${ }^{27}$.

A esta dificultad en el acceso a los alimentos para consumo doméstico cabe agregar las limitaciones que se sufren en los espacios públicos. A pesar de estar legalmente obligados, como veremos más adelante, gran cantidad de entes públicos (escuelas, cárceles, hospitales) y privados (empresarios del rubro hotelero y gastronómico) no cumplen con la oferta de opciones de menús libres de gluten. A modo de ejemplo, podemos citar un estudio efectuado en 2012 en Bahía Blanca, en el cual se recogió información de 114 establecimientos gastronómicos sólo un

\footnotetext{
${ }^{24}$ REVISTA Mundo Celiaco. Disponible en: http://www.cedice.com.ar/revista.php. Acceso en: 30 oct. 2019.

${ }^{25}$ APRO, Nicolás. Celiaquía: Por una vida sin TACC Disponible en: http://www.alimentacion.enfasis.com/ articulos/14968-celiaquia-una-vida-tacc. Acceso en: 27 oct. 2019.

${ }^{26}$ ANMAT. PROGRAMA FEDERAL DE CONTROL DE ALIMENTOS. Directrices para la autorización de un alimento libre de gluten. Disponible en: http://www.anmat.gov.ar/Enfermedad_Celiaca/Directrices_Autorizacion_ ALG.pdf. Acceso en: 24 sept. 2018.

${ }^{27}$ UN sueño para muchos. Cámara Argentina de Productores de Alimentos Libres de Gluten - CAPALIGLU. Revista Mundo Celíaco, n. 17, p. 14, Jul. 2015,
} 
55\% poseía opciones de menús libre de gluten. A su vez, de esos establecimientos, sólo un $22 \%$ ofrecían una amplia oferta de menús libres de gluten ${ }^{28}$.

\section{El acceso económico a los alimentos}

La falta de acceso económico a los alimentos es la "ausencia de recursos financieros para comprarlos, debido a los altos precios de los productos o a los bajos ingresos de los consumidores" 29 . Tal como fue evidenciado en el apartado anterior, aun en aquellos casos en que es posible acceder físicamente a productos sustitutivos libres de gluten, estos poseen un costo considerablemente superior en relación a aquellos similares que contienen gluten. Esta situación genera una severa dificultad en el acceso económico a los alimentos: no siempre se puede comprarlos, o bien, se los compra en una menor proporción. Esta problemática adquiere mayor entidad en grupos económicamente vulnerables.

\section{Como destacan Teubal y Rodriguez:}

El acceso a la alimentación [...] depende en primera instancia del poder adquisitivo de las familias o personas de la sociedad. Evidentemente, aquellas familias o estratos sociales con mayores ingresos o riqueza pueden acceder más fácilmente a una alimentación adecuada, no así aquellos con niveles de ingresos o riquezas mínimos. Más allá de la influencia de multiplicidad de factores, incluyendo los culturales, sobre esta problemática, lo que comemos depende en gran medida del lugar que ocupamos en la estructura social y, por consiguiente, de nuestros niveles de ingresos y la relación entre estos y los precios de los alimentos ${ }^{30}$.

Según un estudio publicado en la Revista Mundo Celíaco, una dieta balanceada para un celíaco cuesta al mes " $34 \%$ más que a las personas no celíacas" y "los productos industrializados (harinas, fideos, galletitas, pan, etc.) permitidos cuestan un 73\% más comparado con los productos industrializados para no celíacos"31.

En Argentina, el alto costo de los productos libres de gluten se vincula a: (i) el elevado costo de las harinas sustitutas del trigo (mandioca, harina de arroz,

\footnotetext{
${ }^{28}$ CRUCIANI, Tomás. Turismo accesible en Bahía Blanca: celiacos, un segmento a integrar. Tesis de Grado de Licenciatura en Turismo, Universidad Nacional del Sur, Bahía Blanca, 2012. Disponible en: http://repositoriodigital.uns.edu.ar/handle/123456789/3300.

${ }^{29}$ ORGANIZAÇÃO das Nações Unidas para a Alimentação e a Agricultura - FAO. Seguridad Alimentaria y Nutricional - Conceptos Básicos. 3. ed. Feb. 2011. Disponible en: http://www.fao.org/3/a-at772s.pdf Acceso en 12 abr. 2019. p. 4.

${ }^{30}$ TEUBAL, Miguel; RODRÍGUEZ, Javier. Agro y alimentos en la globalización: una perspectiva crítica. Buenos Aires: Editorial La Colmena, 2002. p. 136.

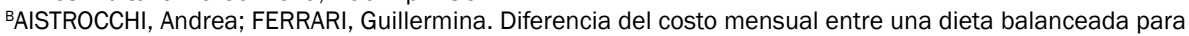
celíacos y una balanceada para no celíacos. Revista Mundo Celíaco, n. 11. p. 16-17, 2012.

${ }^{31}$ ld. Ibid., p. 16-17.
} 
almidón de maíz); (ii) el elevado precio de los aditivos que sustituyen las propiedades del gluten, los cuales son mayormente importados; (iii) los costos adicionales para acreditar periódicamente la condición libre de gluten de los productos ante el Instituto Nacional de Alimentos (INAL), dependiente de la Administración Nacional de Medicamentos, Alimentos y Tecnología Médica (ANMAT); (iv) y los encarecimientos en las cadenas de distribución ${ }^{32}$.

En el mercado argentino, el setenta por ciento de los productos manufacturados contienen gluten, por esto es importante no sólo eliminar de la dieta los cereales que contienen T.A.C.C. sino también "todos aquellos productos en que la industria alimenticia utiliza el gluten para otros fines, por ejemplo: espesante, emulsionantes, etc."33.

Para poder inscribir un producto alimenticio como libre de gluten en Argentina, su elaborador debe presentar documentos ante la autoridad sanitaria de su jurisdicción con los "análisis que "avalen la condición de libre de gluten otorgados por un organismo oficial o entidad con reconocimiento oficial" y un "programa de buenas prácticas de fabricación con el fin de asegurar la no contaminación [...] desde la recepción de las materias primas hasta la comercialización del producto" ${ }^{34}$.

\section{La falta de información}

Más allá de la accesibilidad física y económica de los alimentos libres de T.A.C.C., existe una dificultad adicional a la hora de adquirir alimentos libres de gluten dado que no todos los productores informan con precisión en sus etiquetas si contienen o no gluten ${ }^{35}$.

El derecho a la información de los consumidores es un derecho fundamental que se encuentra reconocido en el ordenamiento jurídico argentino. Está consagrado en el artículo 42, primer párrafo de la Constitución Nacional ${ }^{36}$; en el artículo 1100 del Código Civil y Comercial ${ }^{37}$, y en el artículo 4 de la Ley de Defensa del Consumidor ${ }^{38}$.

\footnotetext{
${ }^{32}$ GARCÍA, María Elisa. Alimentos libres de gluten un problema aún sin resolver. Invenio: revista de investigación académica, v. 16, p. 123-130, 2006. Disponible en: https://www.redalyc.org/articulo.oa?id=87701609.

${ }^{33}$ BAISTROCCHI, Andrea; FERRARI, Guillermina. op. cit., p. 16.

${ }^{34}$ Id. Ibid., p. 14.

${ }^{35}$ MEDINA, G.; LUFT, E. op. cit., p. 2.

${ }^{36}$ ARGENTINA. Constitución de la Nación Argentina. Disponible en: http://servicios.infoleg.gob.ar/ infolegInternet/anexos/0-4999/804/norma.htm. Acceso en: 13 agosto 2021.

${ }^{37}$ ARGENTINA. Código Civil y Comercial de la Nación. Disponible en: http://servicios.infoleg.gob.ar/ infolegInternet/anexos/235000-239999/235975/norma.htm. Acceso en: 13 agosto 2021.

${ }^{38}$ ARGENTINA. Ley 24240, de 22 septiembre 1993. Normas de Protección y Defensa de los Consumidores - Ambito de aplicación - Autoridad de aplicación procedimientos y sanciones - Disposiciones finales. Disponible en: http://servicios.infoleg.gob.ar/infoleglnternet/verNorma.do?id=638. Acceso en: 01 abr. 2019.
} 
Existe una "ausencia de comunicación visual a través del sello sin TACC sobre la existencia de un menú para celíacos" ${ }^{39}$, situación que muchas veces se reproduce en establecimientos públicos alimentarios que cuentan con menús sin T.A.C.C. . En este caso, a pesar de que el alimento sea física y económicamente accesible, existe una deficiente comunicación entre el productor-elaborador y el consumidor, lo que una vez más representa una barrera para acceder efectivamente al producto libre de gluten.

Las publicaciones realizadas por la propia comunidad de celíacos insisten sobre esta dificultad:

estamos convencidos que estar bien informados nos ayuda a disipar dudas y erradicar miedos derribando barreras culturales (...) De la misma forma creemos que la información es el instrumento ideal para sensibilizar a toda la sociedad, permitiendo tomar conciencia y lograr así una mejor integración del celíaco en la comunidad ${ }^{40}$.

Es por ello que la movilización impulsada desde estos movimientos concentró durante años sus reclamos precisamente en la regulación de la confección, actualización y continua fiscalización por parte del Estado de las listas de alimentos sin T.A.C.C. y en la obligatoriedad de la colocación del logo que los distingue en cada producto.

\section{La progresiva conformación de una legislación especial sobre celiaquía}

En este apartado realizaremos el mapeo de la legislación destinada a la protección de las personas con celiaquía. Se identifican dos grandes períodos, marcados por la sanción de la LNC en el año 2009.

\section{Antecedentes}

En el año 1979, la Comisión del Codex Alimentarius aprueba el estándar Codex Stan 118/1979 ${ }^{41}$, norma relativa a los alimentos para regímenes especiales destinados a personas intolerantes al gluten. Fue una de las primeras normas internacionales

\footnotetext{
${ }^{39}$ CRUCIANI, Tomás. op. cit., p. 50.

${ }^{40}$ EDITORIAL. Revista Mundo Celiaco, n. 2, ago. 2007. Disponible en: http://www.cedice.com.ar/revista.php. Acceso en: 30 oct. 2019. En la misma publicación (la primera que se lanza) el organismo Centro de Difusión de la Celiaquía se autodefine como una "organización civil sin fines de lucro que surgió como respuesta a la necesidad de un grupo de celíacos y familiares de difundir la temática en forma integral, considerando que la información es el instrumento principal para comenzar a concientizar a la sociedad sobre la problemática de la celiaquía". EDITORIAL. Revista Mundo Celiaco, cit., p. 3, ago. 2007.

${ }^{41}$ ARGENTINA. Norma del Codex para Alimentos “Exentos de Gluten" Codex Stan 118 - 1981 (Enmendada en 1983). Disponible en: http://www.alimentosargentinos.gob.ar/contenido/marco/Codex_Alimentarius/ normativa/codex/stan/118-1981.PDF. Acceso en: 13 agosto 2021.
} 
en la materia y, con enmiendas en 1983 y 2015, se encuentra aún vigente. El objetivo fundamental de la norma Codex Stan 118/1979 es generar una regulación uniforme a nivel mundial en materia de celiaquía. Determina que las decisiones relativas a la comercialización de estos productos podrán adoptarse a nivel nacional y que todos los productos regulados por la norma deben ser preparados siguiendo buenas prácticas de fabricación (BPF) para evitar la contaminación con gluten.

En relación al etiquetado, este estándar internacional dispone queel término 'exento de gluten' debe figurar en la etiqueta muy cerca del nombre del alimento. En el caso de los alimentos procesados para reducir el contenido de gluten, deja librada la regulación al nivel nacional, pero aclarando que estos productos no pueden denominarse "exentos de gluten".

La primera normativa alimentaria horizontal de alcance nacional que se dicta en el país fue el Reglamento Químico Nacional ${ }^{42}$. Este no preveía aún ninguna norma particular sobre la cuestión celíaca. Tomando como base ese texto, en julio de 1969 se aprueba el Código Alimentario Argentino (CAA ${ }^{43}$. La reglamentación de este código incluyó, entre otras modificaciones, algunas referencias a la cuestión celíaca. A modo de ejemplo, en el capítulo XXVII (sobre "Productos de régimen o dietéticos") encontramos, bajo el título "Alimentos dietéticos pobres en gluten", dos artículos: una definición legal del término y las exigencias del rotulado de estos productos, sin determinar umbrales mínimos.

Más tarde se incluyó en el capítulo V del CAA (titulado "Normas para la Rotulación y Publicidad de los Alimentos") el artículo 235 que expresaba: "Se permite la inclusión de la expresión 'Sin T.AC.C.' o del símbolo internacional 'Sin Gluten' en los productos que no contengan trigo, avena, cebada ni centeno o sus componentes proteicos". Sin embargo, la normativa no precisaba valores umbrales de tolerancia de gluten, ni estipulaba qué métodos de verificación y control debían seguirse. Además, la medida era de carácter voluntario.

A partir de los años noventa, cuando Argentina ingresa en el Mercosur, numerosas normas del CAA son modificadas para internalizar las Resoluciones del Grupo Común. El capítulo V del CAA es uno de los más afectados por las modificaciones operadas por las Resoluciones Ministeriales conjuntas. Entre otras, se incorpora al CAA la Resolución Grupo Mercado Común N²1/ 2002 - Reglamento

\footnotetext{
${ }^{42}$ MARICHAL, María Eugenia. El desarrollo del Sistema Nacional de Control de Alimentos en Argentina. Revista de Derecho Agrario y Alimentario, v. 68, n. 28, p. 157-186, 2016.

${ }^{43}$ ARGENTINA. Ley 18284 del Poder Ejecutivo Nacional, de 18 julio 1969. Código Alimentario Argentino. Normas para la producción, elaboración y circulación de alimentos para consumo humano en todo el país. Disponible en: http://servicios.infoleg.gob.ar/infoleglnternet/verNorma.do?id=21841. Acceso en: 01 abr. 2019. El CAA se reglamenta mediante: ARGENTINA. Decreto 2126/1971 del Poder Ejecutivo Nacional, de 30 junio 1971. Código Alimentario Argentino.Texto ordenado y reglamentado. Disponible en: http:// servicios.infoleg.gob.ar/infolegInternet/verNorma.do?id=209207. Acceso: 01 abr. 2019.
} 
Técnico Mercosur para Rotulación de Alimentos Envasados ${ }^{44}$. Esta resolución, al igual que todas las resoluciones que actualizan el CAA, derogaba toda normativa en contrario en el CAA. Así, quedaron derogados los mencionados párrafos del artículo 235 sobre el etiquetado voluntario de productos sin T.A.C.C.

Ya en 1993, la Ley 24.240 de Defensa del Consumidor, expresamente incluyó en su artículo 4 el "deber de información de los proveedores", con el fin de proteger la salud de los consumidores. Se estableció que todo proveedor debe suministrar "en forma cierta, clara y detallada todo lo relacionado con las características esenciales de los bienes y servicios" que brinda. Sin embargo, este deber genérico no es regulado específicamente para la cuestión celíaca hasta el año 1997, cuando se sanciona la Ley $\mathrm{N}^{\circ} 24.827^{45}$. Mediante esta norma se establecía la obligación, en cabeza de elaboradores de alimentos, de informar a la autoridad de aplicación si sus productos detentaban la calidad de libres de gluten, y la obligación, para aquellos productos que no lo contengan, de llevar "impreso en sus envases, envoltorios, marbete, etiqueta o rótulo de modo perfectamente distinguible, el símbolo internacional que indica esa particularidad del producto" (art. 1). A partir de esa información brindada por los elaboradores o importadores, la autoridad de aplicación debía elaborar un Registro de productos aptos para celíacos (art. 3).

Esta primera normativa nacional sobre celiaquía se dirigía centralmente a proteger el derecho a la información de las personas celíacas, pero no contenía medidas ni acciones concretas tendientes a garantizar otros derechos fundamentales como la salud o el acceso a una alimentación adecuada. Esta legislación fue finalmente abrogada en 2009 mediante el dictado de la Ley $\mathrm{N}^{\circ} 26.588$ (que se analiza en el apartado siguiente).

\section{Denuncias y reclamos por las insuficiencias del primer régimen nacional sobre productos sin T.A.C.C.}

Según investigaciones llevadas adelante por el Defensor del Pueblo ${ }^{46}$, durante casi una década después de puesta en vigencia la Ley $\mathrm{N}^{\circ} 24.827$, las autoridades

\footnotetext{
${ }^{44}$ LLAVE OPERATIVA ADUANERA. Resolución Grupo Mercado Común N²1/ 2002 - Reglamento Técnico Mercosur para Rotulación de Alimentos Envasados. Disponible en: http://www.loa.org.ar/legNormaDetalle. aspx?id=4860. Acceso en: 13 agosto 2021.

${ }^{45}$ ARGENTINA. Ley 24.827 - Congreso de la Nación Argentina, de 21 mayo 1997. Establece que a través del Ministerio de Salud y Acción Social, se determinará la lista de productos alimenticios, que contengan o no gluten de trigo, avena, cebada o centeno en su fórmula química, incluidos los aditivos. Disponible en: http://servicios.infoleg.gob.ar/infolegInternet/verNorma.do?id=44035. Acceso en: 01 abr. 2019. Abrogada por el artículo 17 de la Ley 26.588. ARGENTINA. Ley 26.588, de 02 deciembre de 2009. Declárase de interés nacional la atención médica, la investigación clínica y epidemiológica, la capacitación profesional en la detección temprana, diagnóstico y tratamiento de la enfermedad celíaca. http://servicios.infoleg.gob. ar/infolegInternet/anexos/160000-164999/162428/norma.htm. Acceso en: 13 agosto 2021.

${ }^{46}$ ARGENTINA. Resolución 31/2006 - Defensor del Pueblo de la Nación, de 11 abril 2006. Disponible en: http://servicios.infoleg.gob.ar/infolegInternet/verNorma.do?id=115604. Acceso en: 01 abr. 2019.
} 
obligadas no habían confeccionado completamente la lista de alimentos libres de gluten que esta norma ordenaba. En 1998, la Defensoría del Pueblo hace un seguimiento del trámite en el INAL por las "inexplicables demoras para determinar cómo serían identificados los alimentos que resultan aptos para el consumo de estos pacientes celíacos" (Resolución 31/2006) ${ }^{47}$. A lo cual el INAL respondió que sólo inscribía productos importados y que no había incorporado ningún alimento para celíacos porque las provincias no enviaban la información necesaria.

El Defensor entendió que la información disponible era difusa y contradictoria, mostrando "la falta de impulso tanto de las autoridades nacionales como provinciales para conformar un simple registro de alimentos, cuya confección es ordenada por la ley aplicable para satisfacer las necesidades de los pacientes involucrados". También adjuntó que la no confección del registro violatoria no sólo "del derecho a la información, sino del derecho a la salud e implica una disfunción en términos administrativos, además de no advertirse una debida colaboración con la tarea que desarrolla esta Institución".

En 2006 la cuestión aún se encontraba pendiente. El Defensor manifestó entonces que la Ley $\mathrm{N}^{\circ} 24.827$ y su modificatoria Ley $\mathrm{N}^{\circ} 24.953^{48}$ habían puesto bajo la responsabilidad de la autoridad sanitaria una cuestión que "no puede sujetarse a aspectos de orden subjetivo, dado que dicha norma debe cumplirse en armonía con las garantías que prevé nuestra Constitución Nacional". Expresamente reconocía que sólo mediante el listado faltante se podía proteger el derecho a una información adecuada del artículo 42 de la Constitución Nacional y el derecho a la salud de los habitantes, que el Estado debe contribuir a preservar. Para que "tales garantías no se tornen ilusorias", el Defensor formula una recomendación al INAL:

\begin{abstract}
que adopte las medidas necesarias para proceder a la inmediata confección del registro de los productos que resultan aptos para el consumo de enfermos celíacos, previsto por el artículo $3^{\circ}$ de la ley 24.827, el que debe actualizarse bimensualmente y publicarse una vez al año, tal como lo prevé el mencionado texto legal (art. 1, Resolución 31/2006).
\end{abstract}

En 2007 se crea el Programa Nacional de Detección y Control de la Enfermedad Celíaca, mediante Resolución 1560 del Ministerio de Salud Pública. Según las apreciaciones de la comunidad organizada de celíacos, este programa fue un logro

\footnotetext{
${ }^{47}$ Actuación N 1753/98 caratulada: “Defensor del Pueblo de la Nación sobre presunto incumplimiento de la norma que dispone la colocación de un símbolo en las etiquetas de los alimentos aptos para celíacos".

${ }^{48}$ ARGENTINA. Ley 24953 - Congreso de la Nación Argentina, de 15 abril 1998. Sustituyese el párrafo segundo del art. $1^{\circ}$ de la Ley $N^{\circ} 24827$, que estableció que, a través del Ministerio de Salud y Accion Social, se determinaría la lista de productos alimenticios, que contengan o no gluten de trigo, avena, cebada o centeno en su formula química, incluyendo sus aditivos. Disponible en: http://servicios.infoleg.gob. ar/infolegInternet/verNorma.do?id=50749. Acceso en: 01 abr. 2019. Abrogada por el artículo 17 de la Ley $N^{\circ} 26.588$.
} 
importante en la juridización de sus reclamos. Su creación puede considerarse en parte como resultado de las acciones de visibilización del movimiento, como informa el editorial de julio de 2008 de la Revista Mundo Celíaco:

Destacamos además, la importancia de la creación del programa nacional de detección y control de la Enfermedad Celíaca y del cumplimiento de todas las actividades previstas, así como la adhesión de las provincias al mismo, a fin de contribuir a la detección temprana y al fortalecimiento del Sistema Nacional de Control de Alimentos ${ }^{49}$.

Los considerandos de esta resolución reconocen a la celiaquía como "enfermedad con alto grado de incidencia en la población de nuestro país", cuyas características "condicionan la calidad de vida de las personas afectadas y sus familias", por lo que la "detección temprana y el tratamiento oportuno revisten fundamental importancia para evitar complicaciones secundarias de esta patología, para lo cual no existe terapia farmacológica". El Programa incluye la enfermedad celíaca en las políticas de salud pública pero reconoce que la problemática se debe atender en forma integral, por lo que resultaba "ineludible coordinar acciones" con el Ministerio de Desarrollo Social y con las jurisdicciones provinciales.

El programa se transcribe completo en un Anexo de la Resolución 31/2006. Allí se define y fundamenta médicamente a la enfermedad y se la encuadra como "un problema de salud pública". El propósito del programa es "incluir en el Sistema de Salud acciones que favorezcan la atención y cuidado integral de las personas con enfermedad celíaca". Se establecen acciones para promover el conocimiento y la divulgación masiva de las características de la enfermedad, garantizar el acceso al diagnóstico oportuno, la capacitación de los equipos de salud, el desarrollo de la investigación y el fortalecimiento de la capacidad técnica y analítica del Sistema Nacional de Control de Alimentos. Entre las acciones se pueden destacar las campañas de difusión y educación, la elaboración de guías de diagnóstico y tratamiento, la creación de una red de servicios de gastroenterología y laboratorios equipados para realizar serologías y biopsias, el desarrollo de estudios de prevalencia, el fortalecimiento de los laboratorios de la Red Nacional de Laboratorios Oficiales de Análisis de Alimentos (RENALOA) y la organización de un Registro Nacional de la Enfermedad Celíaca.

Más allá de estos avances, los reclamos de la comunidad de personas celíacas continuaron. Según consta en la documentación fotográfica y los relatos recopilados en el sitio del "Grupo Promotor de la Ley celíaca", creado especialmente para organizar el reclamo por una legislación protectora, los reclamos incluyeron, entre otras

\footnotetext{
${ }^{49}$ EDITORIAL. Revista Mundo Celiaco, n. 4, p. 3, jul. 2008. Disponible en: http://www.cedice.com.ar/revista. php. Acceso en: 30 oct. 2019.
} 
medidas, manifestaciones ante el Congreso de la Nación. El espacio está conformado por un grupo de personas que padecen celiaquía, sus, familiares y amigos que se contactaron con el finde lograr una ley para la defensa de derechos de las personas afectadas por la celiaquía. ${ }^{50}$.

\section{La protección de la Ley Nacional de Celiaquía}

El 2 de diciembre del año 2009 se sanciona la Ley 26.588 sobre la enfermedad celíaca, su difusión y el acceso a los alimentos libres de gluten. El objetivo del desarrollo normativo fue complementar la legislación preexistente ya que, tal como se analizó en el apartado anterior, la normativa predecesora sólo protegía el derecho a la información. Es modificada en 2015 mediante Ley No27.196 ${ }^{51}$. Sobre las modificaciones, en primer lugar, se incorpora una ampliación del ámbito de aplicación (que había sido establecido mediante Resolución de ANMAT) abarcando también a los medicamentos y especialidades medicinales, que deberán cumplir los mismos requerimientos que los alimentos. Cuando se empleen ingredientes que contengan gluten se debe incluir en forma clara y visible la leyenda "Este medicamento contiene gluten". Segundo, se establece que los montos de cobertura parcial de la dieta deberán ser actualizados periódicamente; $y$ tercero, se hace obligatorio para ciertas instituciones públicas, ofrecer una opción de alimentos o menú libre de gluten.

Puede interpretarse que la LNC de 2009 y sus modificatorias, vienen a organizar un régimen jurídico estableciendo diversas medidas de protección que regulan en detalle los derechos humanos a la salud y la alimentación de las personas celíacas. A continuación, analizaremos tres tipos de medidas que se identifican en la norma.

\section{Medidas de protección directa}

A través de estas medidas, el Estado asume un rol más activo para asegurar el acceso a los alimentos libres de T.A.C.C., o bien genera obligaciones en cabeza de privados para que estos colaboren en garantizar dicho acceso.

Entre los instrumentos de protección directa, en primer lugar, cabe mencionar la declaración de interés nacional que recibe "la acción médica, la investigación clínica y epidemiológica, la capacitación profesional en la detección temprana, diagnóstico y tratamiento de la enfermedad celíaca, su difusión y el acceso a los alimentos y medicamentos libres de gluten" (art. 1 de la LNC). Si bien en el Programa Nacional de Detección y Control de la Enfermedad Celíaca ya se había declarado este interés

\footnotetext{
${ }^{50}$ Ver antecedentes en: https://www.facebook.com/GPLeyCeliaca/ Acceso: 22/09/2021.

${ }^{51}$ ARGENTINA. Ley 27196 - Congreso de la Nación Argentina, de 07 octubre 2015. Salud pública. Ley $N^{\circ} 26588$ - Modificación. Disponible en: http://servicios.infoleg.gob.ar/infoleglnternet/verNorma. do?id=255225. Acceso en: 01 abr. 2019.
} 
en 2007 (Resolución 1560 del Ministerio de Salud Pública) es importante su consagración en un texto legislativo por el valor interpretativo que reviste este artículo de la ley en caso de conflicto de las restantes disposiciones u otra norma aplicable.

Por otro lado, la LNC prevé en sus artículos 9 y 10,respectivamente, dos derechos subjetivos en relación al acceso económico a los alimentos libres de gluten. El primero determina que las obras sociales, entidades de medicina prepaga y demás agentes que brinden servicios médicos asistenciales a sus afiliados, independientemente de la figura jurídica que posean, tienen la obligación de proveer a sus afiliados una cobertura asistencial consistente en los costos necesarios para detectar, diagnosticar, dar seguimiento y tratar la enfermedad, como así también, cubrir el valor de las harinas y premezclas libres de gluten.

El artículo 10 de la LNC estipula que el Ministerio de Desarrollo Social de la Nación debe concretar acuerdos con las jurisdicciones locales a fin de proveer a los sujetos no comprendidos en el artículo 9 -es decir, personas no afiliadas a obras sociales o entidades de medicina prepaga- las harinas y premezclas libres de gluten.

Estas medidas tienden a facilitar a las personas celíacas el acceso económico a los alimentos, en consonancia con los postulados del "corpus" internacional de los derechos humanos. En el caso del artículo 9 (asistencia a quienes poseen una cobertura médica) el vínculo establecido entre la persona y su respectiva obra social o prepaga, será una relación de consumo. Es por ello que, ante posibles incumplimientos, serán aplicables las normas de la Ley de Defensa del Consumidor.

El artículo 9 establece en cabeza de las entidades prestatarias de servicios de salud, la obligación de brindar una cobertura asistencial que incluya las harinas, premezclas y otros productos industrializados libres de gluten. El monto de la prestación es determinado por la Secretaría de Gobierno de la Salud de la Nación, y surge de la diferencia existente entre el precio de la Canasta Básica Alimentaria (CBA), publicado mensualmente,y la CBA Sin T.A.C.C., publicado en junio y diciembre, que elabora periódicamente el Instituto Nacional de Estadísticas y Censos (INDEC).

En un principio, el decreto reglamentario de la LNC determinó que el monto de la prestación debía alcanzar un 70\% de la diferencia de precio de harinas y premezclas libres de gluten respecto de aquellas que poseen gluten. Sin embargo, en la práctica, este mecanismo no permitió precisar adecuadamente el alcance la de prestación de las obras sociales, lo que derivó en un alto nivel de litigiosidad. La modificación de la LNC que tuvo lugar en 2015 estableció que el monto de esta cobertura debía ser determinado por el Ministerio de Salud y actualizarse periódicamente conforme al Índice de Precios al Consumidor del INDEC. Ello derivó en la sanción de resoluciones ministeriales que actualizaban el estipendio mensual a cargo de las obras sociales. No obstante, tal como han señalado desde las asociaciones de celíacos, esta medida resultó infructuosa ya que no se precisó una periodicidad en 
la actualización del monto. Desde la reglamentación de la LNC se han dictado tres resoluciones ministeriales actualizando el monto, con una periodicidad irregular.

La Secretaría de Gobierno de Salud de la Nación rubricó en febrero de 2018 un convenio con el INDEC para la confección de una CBA Sin T.A.C.C. Esta información es finalmente publicada en diciembre de 2018 en el informe "INDEC Informa" ${ }^{52}$. Allí se estableció que la CBA Sin T.A.C.C detentaba en junio de 2018 el valor de $\$ 3.533,23$ contra $\$ 2.537,45^{53}$ de la CBA con gluten, por lo que los sujetos obligados por el artículo 9 de la LNC deben abonar a sus afiliados celíacos un estipendio de $\$ 995,78$.

El artículo 10 de la LNC está destinado a brindar asistencia a aquellas personas que no se encuentran afiliadas a ninguna obra social o entidad de medicina prepaga. Para estos casos, la LNC determina que el Estado Nacional será el encargado de otorgar las "harinas y premezclas libres de gluten". El Estado asume el compromiso de proporcionar estos alimentos por medio del Ministerio de Desarrollo Social, para lo cual celebrará acuerdos con las jurisdicciones locales. En este sentido, el Gobierno Nacional destaca que si la persona carece de "cobertura explícita está garantizado el beneficio por el Estado y dicha constancia debe presentarse en la dependencia de Desarrollo Social que corresponda a su jurisdicción" ${ }^{\prime 54}$.

Por otro lado, la Ley N²7196, que modificó la LNC, incorporó una disposición importante sobre la garantía del acceso: la obligatoriedad de ofrecer una opción de alimentos o menú libre de gluten -cumpliendo con las condiciones de manufactura y los requerimientos nutricionales por porción- en determinadas instituciones y establecimientos (art. $4^{\circ}$ bis) ${ }^{55}$. Esta disposición fue recibida por la comunidad de personas celíacas como "un avance muy importante para el cumplimento de la dieta del paciente celíaco y su integración en la sociedad". Como punto "conflictivo a desarrollar" se observó que esa obligación se dispone en forma horizontal sin diferenciación entre distintos tipos de establecimientos ${ }^{56}$. Es interesante cómo, a partir de esta regulación indiscriminada de la ley, la comunidad celíaca se siente interpelada y refuerza su llamado a involucrarse y ser tenidos en cuenta: "debemos participar, contribuyendo con los diferentes puntos de vista, para lograr una reglamentación

\footnotetext{
${ }^{52}$ INDEC Informa, año 23, n. 11, p. 189, nov. 2018. Disponible en: https://sitioanterior.indec.gob.ar/ftp/ cuadros/publicaciones/indecinforma/indec_informa_11_18.pdf.

${ }^{53} \mathrm{En}$ ese momento, la CBA Sin T.A.C.C. tenía un costo de 138 dólares estadounidenses mientras que la CBA con gluten tenía un valor de 99 dólares estadounidenses. Resultado tomando como referencia la cotización del Banco Nación de la República Argentina, el día 1 de junio de 2018.

${ }^{54}$ SALUD e INDEC definieron canasta básica de alimentos para celíacos. Argentina.gob., 10 dic. 2018. Disponible en: https://www.argentina.gob.ar/noticias/salud-e-indec-definieron-canasta-basica-dealimentos-para-celiacos. Acceso en: 01 abr. 2019.

${ }^{55}$ Mencionados en una enumeración no taxativa (esto se deduce del inc. i) de instituciones y establecimientos que deben velar por el cumplimiento de dicha obligación.

${ }^{56}$ EDITORIAL. Revista Mundo Celiaco, n. 19, p. 3, jul. 2016. Disponible en: http://www.cedice.com.ar/revista. php. Acceso en: 30 oct. 2019.
} 
que tome en cuenta las necesidades de los celíacos y que sea de aplicación efectiva". Explican que "si bien la propuesta nos parece en principio una buena forma de empezar a encuadrar el tema; lo que más nos preocupa es cómo se llevará a cabo la fiscalización y desde qué organismos de control, por lo que consideramos habrá que definir en la reglamentación un esquema sencillo y de cumplimiento posible. Mientras no se garantice una correcta fiscalización, no debería ser obligatorio, sino voluntario en aquellos comercios que hayan recibido una correcta capacitación en la elaboración y venta de productos para celíacos" 57 .

\section{Medidas de fiscalización y promoción}

Se trata de instrumentos que establecen los parámetros de control y ejecución, así como la confección y actualización de un registro de productos aptos, y establecimiento de las consecuencias de su infracción. Estas medidas cumplen una función muy importante para los consumidores celíacos: verifican que el contenido de los productos se ajuste efectivamente a lo detallado en el rotulado de los mismos ${ }^{58}$.

El artículo 3 de la LNC establece que la autoridad de aplicación deberá determinar los valores umbrales para que un producto sea considerado libre de gluten. La ANMAT es la encargada de estipular los métodos de análisis para ello. Estas cuestiones se reglamentan en los artículos 1383 y 1383 bis del CAA, que determina que: (i) será alimento sin T.A.C.C. el que no contenga gluten en una proporción mayor a $10 \mathrm{mg} / \mathrm{kg}$; (ii) para determinar la presencia de prolaminas de gluten en los alimentos se utilizará la metodología analítica basada en la Codex Stan 118/79. La etiqueta o rotulado del producto es considerada el elemento esencial de comunicación entre productor y consumidor, por lo tanto, es menester un continuo control y fiscalización de los productos rotulados como "libres de gluten" 59 .

La LNC tiene otras técnicas más "blandas” para la promoción de los derechos protegidos, como el deber de promoción de las condiciones de buenas prácticas de manufactura para la elaboración y el control de los productos alimenticios y de los medicamentos, tarea que pone en cabeza de la autoridad de aplicación, quien debe coordinar acciones con los laboratorios de bromatología y de especialidades medicinales (art. 6 LNC).

\footnotetext{
${ }^{57}$ EDITORIAL. Revista Mundo Celiaco, n. 19, cit., p. 3.

${ }^{58}$ Según la Corte Interamericana de Derechos Humanos (Poblete Vilches Vs. Chile, 2017), siguiendo la Observación General N ${ }^{\circ} 14$ del Comité de DESC, el control y la fiscalización desarrollados por el Estado dentro del sistema de salud, deben garantizar ciertos principios o estándares básicos: disponibilidad, accesibilidad, aceptabilidad y calidad. En lo que atañe a este trabajo, la accesibilidad se entiende como "las dimensiones superpuestas de no discriminación, accesibilidad física, económica y acceso a la información, proveyendo de esta forma un sistema de salud inclusivo basado en los derechos humanos" (párrafo 121).

${ }^{59}$ ANMAT. PROGRAMA FEDERAL DE CONTROL DE ALIMENTOS. Directrices para la autorización de un alimento libre de gluten, cit.
} 
La LNC también prevé medidas de sanción que no serán abordadas, pues la propia dinámica y complejidad de la cuestión, merece un análisis en profundidad, que excede el marco metodológico del presente trabajo. En este sentido, debe destacarse que las sanciones se direccionan a través de procedimientos administrativos que no tienen difusión pública, por lo que no se puede precisar con un alto grado de certeza, el nivel de eficacia que han detentado estas sanciones.

\section{Medidas vinculadas a la información}

Por intermedio del acceso a la información adecuada se posibilita el ejercicio del derecho a la salud de las personas celíacas. La LNC establece obligaciones tanto para el Estado nacional como para los particulares vinculados a la industria alimentaria.

En cuanto a las obligaciones de elaboradores, productores e importadores de productos alimenticios y medicamentos, según lo disponen los artículos 4,7 y 8 de la LNC, todos aquellos que deseen comercializar productos alimenticios o medicamentos libres de gluten, deberán acreditar su condición según el procedimiento que consta en el artículo 3 (art. 7). Asimismo, deberán llevar en sus envoltorios, envases, rótulos o prospectos, de manera claramente visible, la leyenda "Libre de Gluten" y el símbolo que establezca la autoridad de aplicación (art. 4). Se impone también la obligación de difundir, publicitar o promocionar dichos productos alimenticios y medicamentos con la leyenda "libre de gluten" o "Este medicamento contiene gluten" respectivamente (art. 8).

En consonancia con las obligaciones establecidas en esta ley, se modificó el CAA, que actualmente establece normas sobre productos sin T.A.A.C. en su artículo 1383. En primer lugar define qué se entiende por alimento libre de gluten, cuáles son los umbrales de contenido de gluten y cuál es la metodología analítica (siguiendo la normativa global Codex Stan 118-1979). Luego establece requisitos en relación al etiquetado: "Estos productos se rotularán con la denominación del producto que se trate seguido de la indicación "libre de gluten" debiendo incluir además la leyenda "Sin T.A.C.C. " en las proximidades de la denominación del producto con caracteres de buen realce, tamaño y visibilidad. Finalmente establece las condiciones que deberán cumplir tanto productores nacionales como importadores para la aprobación de este tipo de alimentos. Cabe resaltar que el símbolo correspondiente a la leyenda "Sin TACC", se encuentra determinado en el artículo 1383 bis del CAA ${ }^{60}$.

\footnotetext{
${ }^{60}$ ARGENTINA. Resolución Conjunta 131/2011 - Secretaria de Políticas, Regulación e Institutos y Resolución Conjunta 414/2011 - Secretaría de Agricultura, Ganadería y Pesca, de 08 julio 2011. Código Alimentario Argentino. Modificación. Disponible en: http://servicios.infoleg.gob.ar/infoleglnternet/verNorma. do?id=184719. Acceso en: 01 abr. 2019.
} 
En lo que respecta a las obligaciones del Estado Nacional, cabe también agregar la disposición del artículo 5 de la LNC por la cual el Ministerio de Salud deberá confeccionar un registro de los alimentos y medicamentos aptos que se comercialicen en el país, el cual se actualizará bimestralmente y se publicará una vez al año ${ }^{61}$.

\section{La judicialización de los conflictos persistentes}

En este apartado se intenta dar cuenta de las problemáticas que, luego de la sanción de la LNC, continúan afectando a las personas celíacas. Para ello, se analizan algunas causas judiciales de distintos tribunales argentinos, sobre aspectos relevantes de la cuestión.

El corpus analizado consta de cuatro casos. Para efectuar el relevamiento jurisprudencial se utilizaron los siguientes parámetros de búsqueda: (i) período de tiempo considerado: 1/1/2010 a 31/12/2017; (ii) base de datos: Revista La Ley; (iii) palabras claves que se utilizaron como filtros de búsqueda: celiaquía, enfermedad celíaca, intolerancia al gluten; (iv) jerarquía del tribunal: Corte Suprema de Provincia, Tribunal Superior de Provincia, Cámaras Provinciales de Apelaciones, Cámaras Federales de Apelaciones, Cámaras Nacionales de Apelaciones.

El asunto más debatido es la insuficiencia del estipendio establecido por la Resolución del Ministerio de Salud de la Nación para costear el mayor valor que detentan los productos sin gluten. En este sentido, el Caso "F. M. A. c. Swiss Medical S. A. y otro s/amparo" de la Cámara Nacional de Apelaciones en lo Civil y Comercial Federal (Sala I) fallado en el año 2014. La señora M. A. F., promovió acción de amparo (con medida cautelar) contra Swiss Medical S. A. y la Obra Social de Personal de Dirección Acción Social de Empresarios, a fin de que le provea cobertura de los alimentos libres de gluten para el tratamiento que necesita debido a su padecimiento -celiaquía-. La actora fundó su petición en la inconstitucionalidad del decreto reglamentario 528/2011 y en la resolución del Ministerio de Salud $407 / 2012$. El juez de primera instancia decidió hacer lugar a la medida cautelar solicitada disponiendo que Swiss Medical abone una suma de $\$ 900^{62}$. Asimismo, en cuanto al fondo de la cuestión, decidió hacer lugar a lo solicitado y dispuso que Swiss Medical abone una suma de dinero suficiente para solventar el $70 \%$ de la diferencia del monto del costo de los alimentos libres de gluten con aquellos que no lo son. Dicho pronunciamiento se fundó en la inconstitucionalidad de la

\footnotetext{
${ }^{61}$ El Listado de Alimentos Libres de Gluten se encuentra disponible las veinticuatro horas del día en la página web de la ANMAT. ANMAT. PROGRAMA FEDERAL DE CONTROL DE ALIMENTOS. Alimentos libres de gluten. Disponible en: http://www.anmat.gov.ar/Alimentos/libres_gluten/Alimentos_Libres_de_Gluten.asp.

${ }^{62} \mathrm{En}$ el momento del pronunciamiento, el monto de la cobertura que deben proporcionar los sujetos obligados era de \$215, según Resolución del Ministerio de Salud 407/2012. ARGENTINA. Resolución 407/2012 - Ministerio de Salud. Disponible en: https://www.argentina.gob.ar/normativa/nacional/ resoluci\%C3\%B3n-407-2012-196031. Acceso en: 14 agosto 2021.
} 
normativa citada ut supra, ya que los montos estatuidos de la cobertura no permiten garantizar el derecho a la salud, la propiedad y la igualdad.

Este pronunciamiento fue apelado por la actora y las codemandadas. En segunda instancia, el Tribunal consideró que el monto reconocido por el Artículo $1^{\circ}$ de la Resolución 407/2012 del Ministerio de Salud debe ser calificado como irrazonable e inconstitucional, ya que esta cobertura es insuficiente para afrontar los gastos de una enfermedad cuya protección fue declarada de interés nacional. Señaló que "la interpretación de las normas aplicables al caso debe ser formulada asignando pleno efecto a la voluntad del legislador y teniendo en cuenta el contexto general de las leyes y los fines que la informan". Continúa explicando que: "sentado lo expuesto y analizando el conjunto de normas aplicables al caso, se puede concluir que la intención del legislador ha sido la de garantizar la completa protección al celíaco, promoviendo una mejor calidad alimentaria que preserve el derecho a la salud y el acceso al diagnóstico y tratamiento de la enfermedad que padece". En virtud de lo expuesto, la Cámara decide confirmar la sentencia de Primera Instancia, ordenando el pago de una suma periódica mensual de \$900, la cual se actualizará en la medida en que se demuestre fehacientemente que los alimentos que componen la dieta sufran algún incremento sustancial en su costo.

Esta sentencia condenatoria muestra que, a fin de garantizar los derechos constitucionalmente reconocidos -en el sub examine, el tribunal hace expresa mención al derecho a la salud- debe propenderse a la consolidación de un ordenamiento jurídico armónico, en el cual las normas inferiores -también llamadas instrumentales- se adecuen a lo preceptuado por los tratados internacionales, la Constitución Nacional y las leyes nacionales.

En segundo lugar, se detecta de los casos analizados que también el propio Estado incumple las obligaciones de proveer alimentos libres de gluten dentro de los establecimientos públicos (art. 4 bis, LNC). En el caso "Infante, María Miguelina c. Ministerio de Educación de Río Negro s/ Amparo" del año 2015, es el Estado provincial quien incumple con las medidas de protección estatal directa. En el sub judice, María Miguelina Infante en representación de su hija Tamara, menor de edad, interpone acción de amparo debido a que la Escuela $\mathrm{N}^{\circ} 337$ de la localidad de El Bolsón le ha negado los alimentos acordes a su patología -celiaquía- por no poder garantizar la inocuidad de los mismos. Cabe destacar que la niña asiste a dicho colegio bajo la modalidad de jornada extendida -incluye almuerzo en el comedor escolar y que en reiteradas reuniones y notas remitidas, el Consejo Provincial de Educación aclaró que no podía brindar el servicio.

Corrido el traslado de la demanda de amparo, el Ministerio de Educación y Derechos Humanos elabora el respectivo informe, ratificando la imposibilidad de cumplimentar lo requerido, debido a la falta de recursos humanos y materiales para garantizar la salud de la niña. Agrega la recomendación de que los alimentos 
los aporte el adulto conviviente para asegurarse que sean elaborados con los cuidados indispensables.

El Tribunal hace lugar al pedido de la Sra. Infante, fundándose en numerosos tratados internacionales de derechos humanos que tutelan el derecho a la salud y el interés superior del niño, en la normativa Nacional -Ley 26.588- y Provincial -Leyes 3772, 4007 y 4784-, compeliendo al Ministerio de Educación y Derechos Humanos de la Provincia de Río Negro a arbitrar los medios necesarios para garantizar la provisión de alimentos libres de gluten a la niña diagnosticada como celíaca dentro del plazo de 90 días, bajo apercibimiento de remitir las actuaciones a sede penal.

En el caso "Vidal Valenzuela Marcos Esteban s/ Ejecución Anticipada", una persona privada de la libertad con diagnóstico de celiaquía, que mantenía un peso de diez kilogramos por debajo del correspondiente a su condición y que no podía acceder a alimentos aptos con adecuados recaudos de higiene en su lugar de detención, solicitó ser autorizada a cumplir la pena privativa de libertad en su domicilio. El juez del Tribunal Oral en lo Criminal Federal de General Roca (año 2014) dispuso la prisión domiciliaria, apoyándose en la normativa nacional referente a Ejecución de Penas, debido a que el establecimiento penitenciario, no brindaba una alimentación acorde a su situación. Es menester remarcar que la decisión del juez no se fundó en una transgresión a la LNC -a pesar de encontrarse vigente al momento de los hechos-. Tampoco se impuso sanción alguna al Estado Nacional por el incumplimiento al artículo $4^{\circ}$ bis de la LNC, ni se lo conminó al cumplimiento efectivo.

Por último, se detecta una insuficiente divulgación y difusión de los derechos previstos en la LNC. En el Caso "Consumidores Libres Cooperativa LTDA de Provisión de Servicios de Acción Comunitaria c. OSPRERA s/incidente de medida cautelar", la actora demandó a una obra social a fin de que comunique a todos los usuarios que los celíacos tienen derecho al cobro de una suma fija determinada por la autoridad de aplicación para la adquisición de harinas y premezclas libres de gluten, sus derivados y productos elaborados con ellas. La Sala II de la Cámara Nacional de Apelaciones en lo Civil y Comercial Federal (año 2015) ordenó a la demandada "poner en conocimiento de todos sus afiliados el beneficio previsto en el Artículo 7 del Decreto 528/11", ya que estimó que la naturaleza del derecho y el amplio universo de potenciales beneficiarios justifica el pedido de difusión de esta información, ponderando además el criterio general que en este ámbito ha adoptado la Ley de Defensa del Consumidor $N^{\circ} 24.240$.

\section{La (in)eficacia de la regulación especial sobre celiaquía}

Otras fuentes importantes para detectar las problemáticas subsistentes a la sanción de la LNC, son los informes producidos sobre los precios de los alimentos, 
y el impacto que estos tienen en el acceso a la alimentación de las personas celíacas. En este sentido, destacamos la labor del Instituto de Estadísticas del Defensor del Pueblo de la Provincia de Córdoba, que en el marco de su Programa de Relevamiento de Precios, elabora mensualmente un Informe sobre CBA y CBA Sin T.A.C.C. Estas representan un umbral para determinar a las personas que se encuentran bajo la línea de la indigencia, es decir, aquellos sujetos que no poseen ingresos iguales o superiores al monto de la CBA o CBA Sin T.A.C.C. se encuentran en condición de indigentes. Paralelamente, el Instituto de Estadísticas del Defensor del Pueblo (INEDEP) también incorpora en su Informe mediciones relativas a la Canasta Básica Total (CBT) y Canasta Básica Total Sin T.A.C.C., las que representan un umbral para determinar a las personas que se encuentran bajo la línea de la pobreza, es decir, aquellos sujetos que no poseen ingresos iguales o superiores al monto de la CBT o CBT Sin T.A.C.C. se encuentran en condición de pobres.

Tomando como referencia los Informes del INEDEP para el territorio de la Provincia de Córdoba en el período Marzo/Diciembre del año 2017 (10 meses), hemos efectuado un breve estudio analítico-descriptivo que demuestra los mayores costos que enfrentan las familias con integrantes que padecen celiaquía:

(i) Un grupo familiar (compuesto por dos progenitores de 30 años, un niño de 6 años y una niña de 8 años) sin restricciones dietarias relacionadas con la celiaquía, necesitó un ingreso promedio mensual de $\$ 5803,40$ para poder acceder a la CBA con T.A.C.C., mientras que el mismo grupo familiar (dos progenitores, un niño de 6 años y una niña de 8 años) cuya niña de 8 años padece celíaca, necesitó un ingreso promedio mensual de $\$ 6366,07$ para acceder a la CBA Sin T.A.C.C. Esto significa que la CBA Sin T.A.C.C. fue en promedio un 9,69\% más costosa que la CBA con T.A.C.C.

Según detalla el "Informe de Marzo de 2017" del INEDEP

Para la conformación del hogar de la CBA para celíacos se tomó la prevalencia de la enfermedad en la población. Para adultos se estima que es de 1/100. En cambio, para niños (de 7 a 16 años) es mucho más frecuente, teniendo una prevalencia de 1/79. La literatura al respecto también afirma que se presenta más en las mujeres que en los varones. Por esa razón se considera que solo la niña de ocho años es celíaca, y no el resto del hogar ${ }^{63}$.

Sin embargo, es prudente destacar que, al margen de las valoraciones efectuadas por el INEDEP, la EC es una afección de orden genético, por lo que

\footnotetext{
${ }^{63}$ Instituto de Estadísticas del Defensor del Pueblo - INEDEP. Canasta Básica Alimentaria/Canasta Básica Alimentaria para Celíacos. Informe Marzo de 2017. Disponible en: https://www.defensorcordoba.org.ar/ archivos/publicaciones/2017-3-28-14.50.17.789_GaleriaArchivo.pdf . Acceso en: 22 sept. 2021.
} 
generalmente varios de los integrantes de la misma familia detentan la enfermedad. Esto representaría un aumento sustancial en la CBA y CBT sin T.A.C.C.

(ii) Un adulto mayor (varón de entre 30 y 60 años) sin restricciones dietarias relacionadas con la celiaquía, necesitó un ingreso promedio mensual de $\$ 1878,42$ para poder acceder a la CBA con T.A.C.C., mientras que el mismo adulto mayor celíaco necesitó un ingreso promedio mensual de $\$ 2709,57$ para acceder a la CBA Sin T.A.C.C. Esto significa que la CBA Sin T.A.C.C. fue en promedio un 44,24 \% más costosa que la CBA Sin T.A.C.C. En el Gráfico 1 podemos observar la diferencia sustancial entre ambas CBA, que se mantuvo inalterada durante el período de referencia.

(iii) Un grupo familiar (compuesto por dos progenitores de 30 años, un niño de 6 años y una niña de 8 años) sin restricciones dietarias relacionadas con la celiaquía, necesitó un ingreso promedio mensual de \$14.161,11 para poder acceder a la CBT con T.A.C.C., mientras que el mismo grupo familiar (dos progenitores, un niño de 6 años y una niña de 8 años) cuya niña de 8 años es celíaca, necesitó un ingreso promedio mensual de $\$ 15.547,11$ para acceder a la CBT Sin T.A.C.C. Esto significa que la CBT Sin T.A.C.C. fue en promedio un 9,78 \% más costosa que la CBA con T.A.C.C.

(IV) Un adulto mayor (varón de entre 30 y 60 años) sin restricciones dietarias relacionadas con la celiaquía, necesitó un ingreso promedio mensual de $\$ 5040,92$ para acceder a la CBT con T.A.C.C., mientras que el mismo adulto mayor celíaco necesitó un ingreso promedio mensual de $\$ 6611,68$ para acceder a la CBT Sin T.A.C.C. Esto significa que la CBT Sin T.A.C.C. fue en promedio un $31,16 \%$ más costosa que la CBA Sin T.A.C.C.

La falta de acceso físico y económico a alimentos suficientes e inocuos sitúa a los consumidores celíacos en una situación de vulnerabilidad y desigualdad en relación a aquellos consumidores que no padecen restricciones dietarias.

\section{Consideraciones finales}

El breve mapeo cronológico del ordenamiento jurídico aquí reseñado permite entender que la regulación de la enfermedad celíaca atravesó dos etapas. Un primer período que comienza con la reglamentación del CAA en 1971 y abarca hasta la sanción de la LNC (en 2009). En esta etapa se reconocen algunos derechos a las personas celíacas en tanto consumidores de alimentos, fundamentalmente en materia de derecho a la información, pero mediante normas de ejecución voluntaria por parte de los productores de alimentos. Con la creación del Programa Nacional de Detección y Control de la Enfermedad Celíaca en 2006 se la conceptualiza como enfermedad y se le reconoce un lugar en la agenda de políticas de salud pública. 
Se identifica un segundo período a partir de la sanción de la LNC, el cual se dictan normas que reconocen otros derechos fundamentales relacionados con el acceso físico y económico a los alimentos y medicamentos para las personas celíacas, su derecho a la salud y a una alimentación adecuada, con lo cual se visibiliza una comprensión más amplia de la problemática.

Sin embargo, a partir del estudio efectuado, podemos vislumbrar que a pesar de contar con ese marco normativo, la legislación no alcanza un grado adecuado de eficacia en varios aspectos. Centralmente, se observa que los montos de la cobertura prevista para la adquisición de alimentos aptos para celíacos deben ser acordes con los costos reales de los mismos, y que dichos montos deben ajustarse con una periodicidad suficiente para que no se deprecien (aspecto sumamente relevante en un país con los altos índices inflacionarios como el nuestro). Queda por verse si la reciente declaración del INDEC acerca de la elaboración y publicación de una Canasta Básica para Celíacos logra dar respuesta a esta problemática en forma efectiva ${ }^{64}$.

En segundo lugar, es necesario contar con una seria implementación de las medidas que crean obligaciones en cabeza del propio Estado y que éste asuma una activa labor de fiscalización y control del cumplimiento por parte de los privados obligados según la LNC.

La construcción progresiva del régimen protectorio de las personas celíacas permite corroborar la importancia de la intervención estatal para asegurar los derechos económicos, sociales y culturales, en este caso, el derecho a la alimentación. Se trata de proteger a un sujeto de derecho que tiene dificultades para acceder física y económicamente a los alimentos a raíz de una enfermedad que afecta su organismo, por lo que es menester que el Estado desarrolle políticas públicas inclusivas a fin de equiparar la situación de las personas celíacas con la de aquellas que no poseen este tipo de restricciones dietarias.

El caso muestra también la importancia de la movilización y participación ciudadana en la construcción normativa. La LNC es resultado del activismo de las personas afectadas que inicialmente se agruparon para compartir información sobre la afectación y luego entendieron que necesitaban un tipo de protección que debía traducirse en normativa jurídica. Sin embargo, la percepción del universo normativo

\footnotetext{
${ }^{64} \mathrm{~A}$ la fecha, y en base a la poca información disponible, es dable esperar nuevos conflictos en torno a la interpretación de esta medida, ya que no se aclara si los montos que están obligadas a cubrir las Obras Sociales a sus afiliados que padecen celiaquía consta del total de la CBA sin TACC o solamente de la diferencia por el mayor costo de ésta comparativamente con la CBA con gluten. Ver: "Celíacos pidieron a losper que suba las partidas para la canasta de alimentos". Se explica en la nota que el pedido surge luego de que el Indec y la Secretaría de Salud de la Nación definieran que las obras sociales deben cubrir 3.533 pesos para los pacientes celíacos. CELÍACOS pidieron a losper que suba las partidas para la canasta de alimentos. UNO, 05 feb. 2019. Disponible en: https://www.unoentrerios.com.ar/la-provincia/celiacospidieron-iosper-que-suba-las-partidas-la-canasta-alimentos-n1733392.html.
} 
por parte de los grupos movilizados, limitada a la esfera nacional, concentró sus reclamos en la conquista de una legislación nacional que consagra derechos derivados de la noción de salud. Tal vez, debido al fuerte acompañamiento que estas agrupaciones tuvieron por parte de la comunidad médica y de nutricionistas, y en el propio encuadre legal que recibió la afectación desde el Programa Nacional de Detección y Control de la Enfermedad Celíaca (2006), el eje de su reclamo se concentró en la definición de la enfermedad. Este discurso, que cruzó las miradas expertas médica y legal sobre la cuestión celíaca, restringió el ámbito de discusión de la problemática a una afectación a la salud corporal de un "paciente" afectado. Entendemos que esta estrategia, en términos jurídicos, si bien fue exitosa en función del objetivo propuesto (la sanción de una ley nacional), podría ampliarse para remover los obstáculos aún pendientes que se han señalado. El discurso puede enriquecerse desde una comprensión más amplia del universo de derechos que parta del enfoque de derechos, abandonando la medicalización y considerando que el acceso a alimentos sanos, seguros, suficientes y adecuados es un derecho humano protegido constitucional y convencionalmente.

Tal como se ha analizado en el primer apartado de este trabajo, existe una directa vinculación entre el tipo de protección y alcance internacionalmente reconocido del derecho a la alimentación con las problemáticas específicas de la cuestión de la celiaquía: las dificultades en el acceso físico y económico, y la falta de información. Partiendo del derecho a la alimentación comprendido como un derecho humano, la protección de las personas con celiaquía supera el espectro de las políticas sanitarias sectoriales y pasa a formar parte de un discurso mayor.

\section{Referencias}

ANMAT. PROGRAMA FEDERAL DE CONTROL DE ALIMENTOS. Alimentos libres de gluten. Disponible en: http://www.anmat.gov.ar/Alimentos/libres_gluten/Alimentos_Libres_ de_Gluten.asp.

ANMAT. PROGRAMA FEDERAL DE CONTROL DE ALIMENTOS. Directrices para la autorización de un alimento libre de gluten. Disponible en: http://www.anmat.gov.ar/ Enfermedad_Celiaca/Directrices_Autorizacion_ALG.pdf. Acceso en: 24 sept. 2018.

APRO, Nicolás. Celiaquía: Por una vida sin TACC Disponible en: http://www.alimentacion. enfasis.com/articulos/14968-celiaquia-una-vida-tacc. Acceso en: 27 oct. 2019.

BAI, Julio César; CIACCI, Carolina; OLANO GOSSWEILER, Carolina (Eds.). Enfermedad celíaca y sensibilidad al gluten: Clínicas Iberoamericanas de Gastroenterología y Hepatología. [s.l.]: Elsevier, 2015.

BAISTROCCHI, Andrea; FERRARI, Guillermina. Diferencia del costo mensual entre una dieta balanceada para celíacos y una balanceada para no celíacos. Revista Mundo Celíaco, n. 11. p. 16-17, 2012. 
BONET DE VIOLA, Ana María. Entre seguridad, soberanía y democracia alimentaria: consecuencias políticas de una disgregación terminológica. Derecho y Justicia, v. 4, p. 7-23, 2014. Disponible en: https://www.researchgate.net/publication/303786105_Entre_seguridad_ soberania_y_democracia_alimentaria_Consecuencias_politicas_de_una_disgregacion_ terminologica.

CELÍACOS pidieron a Iosper que suba las partidas para la canasta de alimentos. UNO, 05 feb. 2019. Disponible en: https://www.unoentrerios.com.ar/la-provincia/celiacos-pidieroniosper-que-suba-las-partidas-la-canasta-alimentos-n1733392.html.

CRUCIANI, Tomás. Turismo accesible en Bahía Blanca: celiacos, un segmento a integrar. Tesis de Grado de Licenciatura en Turismo, Universidad Nacional del Sur, Bahía Blanca, 2012. Disponible en: http://repositoriodigital.uns.edu.ar/handle/123456789/3300.

EDITORIAL. Revista Mundo Celiaco, n. 19, jul. 2016. Disponible en: http://www.cedice.com. ar/revista.php. Acceso en: 30 oct. 2019.

EDITORIAL. Revista Mundo Celiaco, n. 4, jul. 2008. Disponible en: http://www.cedice.com. ar/revista.php. Acceso en: 30 oct. 2019.

EDITORIAL. Revista Mundo Celiaco, n. 2, ago. 2007. Disponible en: http://www.cedice.com. ar/revista.php. Acceso en: 30 oct. 2019.

GARCÍA, María Elisa. Alimentos libres de gluten un problema aún sin resolver. Invenio: revista de investigación académica, v. 16, p. 123-130, 2006. Disponible en: https://www.redalyc.org/ articulo.oa?id=87701609.

INDEC Informa, año 23, n. 11, nov. 2018. Disponible en: https://sitioanterior.indec.gob.ar/ $\mathrm{ftp} /$ cuadros/publicaciones/indecinforma/indec_informa_11_18.pdf.

Instituto de Estadísticas del Defensor del Pueblo - INEDEP. Canasta Básica Alimentaria/ Canasta Básica Alimentaria para Celíacos. Informe Marzo de 2017. Disponible en: https://www. defensorcordoba.org.ar/archivos/publicaciones/2017-3-28-14.50.17.789_GaleriaArchivo.pdf. Acceso en: 22 sept. 2021.

JACOBI, M. F. et al. Menúes aptos para celíacos y conocimiento de los manipuladores de alimentos en los servicios gastronómicos comerciales de la ciudad de Santa Fe. Actualización en Nutrición, v. 18, n. 4, p. 108-114, 2017.

KNUTH, Lidija; VIDAR, Margret. Constitutional and legal protection of the right to food around the world. Roma: FAO, 2011. (RighttoFoodStudies). Disponible en: http://www.fao. org/docrep/016/ap554e/ap554e.pdf.

MARICHAL, María Eugenia. El desarrollo del Sistema Nacional de Control de Alimentos en Argentina. Revista de Derecho Agrario y Alimentario, v. 68, n. 28, p. 157-186, 2016.

MEDINA, G.; LUFT, E. Los celíacos y las obligaciones de las obras sociales y empresas de medicina prepaga. La Ley, Buenos Aires, p. 1-12, 2010. 
Regulación jurídica sobre seguridad alimentaria de las personas celíacas en Argentina

MEULEN, B. M. J. van der. The functional field of food law. The emergence of a functional discipline in the legal sciences. Wageningen: European Institute for Food Law, 2018. (Working Paper). Disponible en: https://ssrn.com/abstract=3128103.

MEULEN, B. M. J. van der; RĂTESCU, Ioana. Food prints on human rights law paradigms. Wageningen: European Institute for Food Law, 2017. Disponible en: https://ssrn.com/ abstract $=3056750$.

NACIONES UNIDAS. Consejo Económico y Social. El derecho a una alimentación adecuada (art. 11). E/C.12/1999/5, CESCR Observación General 12 (General Comments). Ginebra: ONU, 1999. Disponible en: https://www.acnur.org/fileadmin/Documentos/ BDL/2001/1450.pdf.

NACIONES UNIDAS. Convención sobre Eliminación de todas las formas de Discriminación contra la Mujer. Disponible en: ohchr.org/sp/professionalinterest/pages/cedaw.aspx. Acceso en: 13 ago. 2021.

NACIONES UNIDAS. Convención sobre los Derechos de las Personas con Discapacidad. Disponible en: https://www.un.org/esa/socdev/enable/documents/tccconvs.pdf. Acceso en: 13 ago. 2021.

NACIONES UNIDAS. Declaración Universal de Derechos Humanos. Disponible en: https://www.un.org/es/about-us/universal-declaration-of-human-rights. Acceso en: 13 ago. 2021.

NACIONES UNIDAS. Pacto Internacional de Derechos Económicos, Sociales y Culturales. Disponible en: https://www.ohchr.org/sp/professionalinterest/pages/cescr.aspx. Acceso en: 13 ago. 2021.

ORGANIZAÇÃO das Nações Unidas para a Alimentação e a Agricultura - FAO. Cronología del Derecho a la Alimentación. Disponible en: http://www.fao.org/right-to-food-timeline/es. Acceso en: 25 sept. 2018.

ORGANIZAÇÃO das Nações Unidas para a Alimentação e a Agricultura - FAO. La Utilización de los principios del análisis de riesgos y de los puntos críticos de control en el control de alimentos. Vancouver: Food\&AgricultureOrg., 1996.

ORGANIZAÇÃO das Nações Unidas para a Alimentação e a Agricultura - FAO. La Seguridad Alimentaria: una información importante para la toma de decisiones. Guía Práctica 2011. Disponible en: http://www.fao.org/3/al936s/al936s00.pdf. Acceso em: 04 abr. 2019.

ORGANIZAÇÃO das Nações Unidas para a Alimentação e a Agricultura - FAO. Seguridad Alimentaria y Nutricional - Conceptos Básicos. 3. ed. Feb. 2011. Disponible en: http://www. fao.org/3/a-at772s.pdf Acceso en 12 abr. 2019. p. 4.

ORGANIZACIÓN DE LOS ESTADOS AMERICANOS - OEA. Convención Americana sobre Derechos Humanos. Disponible en: https://www.oas.org/dil/esp/tratados_b-32_convencion_ americana_sobre_derechos_humanos.htm. Acceso en: 13 ago. 2021. 
ORGANIZACIÓN DE LOS ESTADOS AMERICANOS - OEA. Declaración Americana de los Derechos y Deberes del Hombre. Disponible en: http://www.oas.org/es/cidh/mandato/ Basicos/declaracion.asp. Acceso en: 13 ago. 2021.

ORGANIZACIÓN DE LOS ESTADOS AMERICANOS - OEA. Protocolo Adicional a la Convención Americana sobre Derechos Humanos en Materia de Derechos Económicos, Sociales y Culturales - Protocolo de San Salvador. Disponible en: http://www.oas.org/es/sadye/ inclusion-social/protocolo-ssv/docs/protocolo-san-salvador-es.pdf. Acceso en: 13 ago. 2021.

PELLICER, K. et al. Actualización en legislación de alimentos para celíacos. Analecta Veterinaria, v. 34, n. 1-2, p. 26-32, 2014. Disponible en: http://sedici.unlp.edu.ar/bitstream/ handle/10915/45518/Documento_completo.pdf?sequence=1\&isAllowed=y.

POLANCO ALLUÉ, Isabel; RIBES KONINCKX, Carmen. Enfermedad celíaca. Pediatría Integral, v. 1, n. 2, p. 47-54, 1995.Disponible en: https://docplayer.es/6774608-Enfermedadceliaca-isabel-polanco-allue-1-carmen-ribes-koninckx-2.html.

REVISTA Mundo Celiaco. Disponible en: http://www.cedice.com.ar/revista.php. Acceso en: 30 oct. 2019.

SALUD e INDEC definieron canasta básica de alimentos para celíacos. Argentina.gob., 10 dic. 2018. Disponible en: https://www.argentina.gob.ar/noticias/salud-e-indec-definieroncanasta-basica-de-alimentos-para-celiacos. Acceso en: 01 abr. 2019.

SEN, Amartya. Poverty and famines. Oxford: Oxford University Press, 2005.

TEUBAL, Miguel; RODRÍGUEZ, Javier. Agro y alimentos en la globalización: una perspectiva crítica. Buenos Aires: Editorial La Colmena, 2002.

UNICEF. Convención sobre los Derechos del Niño. Disponible en: https:/www.unicef.es/ sites/unicef.es/files/comunicacion/ConvencionsobrelosDerechosdelNino_0.pdf. Acceso en: 13 ago. 2021.

Andrés Jesús Villalba - Abogado por la Universidad Nacional del Litoral. Diplomado en Innovación Política por la University of Arizona. Docente a cargo de la virtualidad de la Asignatura "Derecho Civil IV: Derechos Reales" de la Facultad de Ciencias Jurídicas y Sociales. Santa Fe, Argentina. E-mail: andresjesusvillalba@hotmail.com

María Eugenia Marichal - Doctorado en Derecho por la Universidad Nacional del Litoral; Magíster en Ciencia, Tecnología y Sociedad por la Universidad Nacional de Quilmes; abogada por la Universidad Nacional del Litoral. Docente Adjunta ordinaria dedicación exclusiva en las asignaturas "Filosofía del Derecho" y "Epistemología de las Ciencias Sociales", de la Facultad de Ciencias Jurídicas y Sociales de la Universidad Nacional del Litoral. Investigadora Asistente del Consejo Nacional de Investigaciones Científicas y Técnicas radicada en el Centro de Investigaciones en Derecho de la Universidad Nacional del Litoral. Santa Fe, Argentina. E-mail: marichal@fcjs.unl.edu.ar 